\title{
INTERNATIONAL UNION OF PURE AND APPLIED CHEMISTRY
}

\section{DIMETHYLFORMAMIDE: PURIFICATION, TESTS FOR PURITY AND PHYSICAL PROPERTIES}

\author{
Prepared for publication by \\ JEAN JUILLARD \\ Laboratoire d'Etude des Interactions Solutés-Solvants, \\ Université de Clermont-B.P. 45-63170 Aubière, France
}


$\mathrm{N}, \mathrm{N}^{\prime}$-Dimethylformamide (DMF) is a good solvent for organic and to a lesser extent inorganic compounds. It is, together with dimethylsulfoxide and acetonitrile, one of the most widely used of the so-called dipolar aprotic solvents. Owing to its fairly high dielectric constant, it is a moderately dissociating solvent for electrolytes. Acid-base reactions as well as thermodynamic properties of electrolyte solutions have been studied by many authors. Contrary to the $\mathrm{N}$-methylamides it is a typically weakly associated solvent, as seen (Ref. 1) from dielectric studies (the Kirkwood $\mathrm{g}$ factor is about one at all temperatures).

Owing to its electron-donor character, DMF reacts with many acids. For example, Gutmann's donicity number (Ref. 2) is 27 . Its polarographic range is quite large, e.g., $3.5 \mathrm{~V}$ at the dropping mercury electrode with $0.1 \mathrm{M} \mathrm{Bu}_{4} \mathrm{NClO}_{4}$ as supporting electrolyte (Ref. 3 ). It is therefore widely used as a solvent for electrochemical reactions, especially reductions.

Pure DMF is colorless and, at room temperature, odorless. It is subject to thermal as well as photochemical degradation. In presence of water, DMF is slowly hydrolyzed according to the equation:

$$
\mathrm{HCON}\left(\mathrm{CH}_{3}\right)_{2}+\mathrm{H}_{2} \mathrm{O} \longrightarrow \mathrm{HCOOH}+\left(\mathrm{CH}_{3}\right)_{2} \mathrm{NH}
$$

Formic acid and dimethylamine are thus predominant impurities in DMF and determine the odor of the impure solvent. They are weakly acidic and weakly basic respectively; therefore, partial ionization does occur:

$$
\mathrm{HCOOH}+\left(\mathrm{CH}_{3}\right)_{2} \mathrm{NH} \rightleftharpoons \mathrm{HCOO}^{-}+\left(\mathrm{CH}_{3}\right)_{2} \mathrm{NH}_{2}^{+}
$$

and results in a buffered solution ( $\mathrm{pH}$ 11) with an increase in the conductivity of the solvent.

Thermal degradation produces dimethylamine and carbon monoxide. Hydrogen (Ref. 4) and hydrogen cyanide (Ref. 5) have been identified among the products of the photochemical degradation of the solvent.

Strongly basic media are difficult to obtain in DMF; there is, to our knowledge, no substance behaving as a strong base in DMF. If autoprotolysis of the medium actually occurs, the anion of the solvent must be very unstable (Ref. 6). It has been claimed (Ref. 7 and 8 ) that the autoprotolysis constant is smaller than $10^{-25}$ but no definite value has yet been proposed.

Attention must be paid to the fact that DMF has toxic effects, particularly on the liver and kidneys; the threshold value for air has been fixed (Ref. 9) at $30 \mathrm{mg} / \mathrm{m}^{3}$.

\section{PURIFICATION OF DIMETHYLFORMAMIDE}

Good quality DMF is commercially available. As noted by Vaughn (Ref. 10), spectrograde solvent is not always suitable for all purposes. As a consequence of hydrolysis, the residual water content of commercial DMF is frequently low $(0.1 \%)$. Many procedures have been proposed and used for the purification of the solvent. Four types of successive operation can be distinguished: treatment with a drying agent, neutralization of basic or acidic impurities, careful distillation, and elimination of gaseous impurities.

+Titular Members: R. G. Bates, Chairman (USA); J. F. Coetzee, Secretary, (USA); Members: E. Bishop(UK), T. Fujinaga (Japan), Z. Galus (Poland), J. Jordan (USA), H. W. NUrnberg (FRG), P. Zuman (USA); Associate Members: M. Branica (Yugoslavia), A. K. Covington (UK), L. Gierst

(Belgium), K. Izutsu (Japan), L. Meites (USA), E. Pungor (Hungary), O. A. Songina (USSR), B. Trémillon (France); National Representatives: D. D. Perrin (Australia), G. Kraft (FRG), R.C. Kapoor (India), N. Tanaka (Japan), W. Kemula (Poland), P. O. Kane (UK). 
1. Preparing water-free solvent. Although the boiling point of water is far from that of DMF it is not possible to obtain a dry solvent by distillation only.

One of the first methods proposed for preliminary drying (Ref. 11) was azeotropic distillation with about $10 \%$ by volume of dry benzene; the benzene-water azeotrope is removed by distillation at atmospheric pressure. To prevent decomposition the temperature is maintained below $80^{\circ} \mathrm{C}$. Alternatively, molecular sieves can be used. The solvent is kept in contact for periods ranging from 1 to 4 days with $4 \AA$ (Ref. 12-15) or $5 \AA$ (Ref. 16) sieves which are removed and replaced from time to time. Ritchie (Ref. 17) recommends the use of Linde $A W-500$ molecular sieves in 1/16-inch pellets. Studying drying efficiency, he finds that the water content is less than $18 \mathrm{ppm}$ after 27 hours. Molecular sieves can be dried before use by heating in a quartz tube under a stream of argon at $375^{\circ} \mathrm{C}$ for $24 \mathrm{~h}$ (Ref. 18). Finally, a procedure which uses chromatographic purification through alumina has been described by Moe (Ref. 13) in some detail. "A column approximately $100 \mathrm{~cm}$ long and $5 \mathrm{~cm}$ wide will contain 1 $\mathrm{kg}$ of alumina, sufficient for the purification of about 101 of DMF". After bubbling of pure nitrogen for several hours the DMF thus obtained is thought to be convenient for polarographic use.

In our opinion these three types of operation can be considered only as a first step in drying the solvent, and mild chemical drying agents must also be used. These range from anhydrous $\mathrm{BaO}$ (Ref. 11 and 19) to $\mathrm{MgSO}_{4}$ (Ref. 20), $\mathrm{Na}_{2} \mathrm{CO}_{3}$ (Ref. 6 and 20), or $\mathrm{CuSO}_{4}(\operatorname{Ref} .21$ ). Surprisingly good samples of DMF can be obtained using storage of solvent over these chemicals for at least $24 \mathrm{~h}$. It has been recommended that the drying agent be changed at least twice and the container shaken, if not continuously, at least from time to time. It also has been recommended that such an operation is performed in a cold, dark room. As far as $\mathrm{Na}_{2} \mathrm{SO}_{4}$ or $\mathrm{Na}_{2} \mathrm{CO}_{3}$ are concerned, the resulting solvents are of about the same quality (Ref. 20). Little or no degradation of the solvent (as estimated through the concentration of dimethylamine) results from such treatment (Ref. 11).

Some of the more common drying agents react with the solvent itself to produce significant amounts of acidic or basic impurities. BaO, cited previously, belongs to this category if it is used at temperatures above $30^{\circ} \mathrm{C}$ (Ref. 11). Other reagents are potassium hydroxide, calcium hydride (Ref. 5 and 22) and phosphorus pentoxide (Ref. 17, 23 and 24). $\mathrm{P}_{2} \mathrm{O}_{5}$ is the most frequently used, $\mathrm{CaH}_{2}$ is probably the most efficient. Prue and Sherrington (Ref. 23) have shaken DMF for three days with $\mathrm{P}_{2} \mathrm{O}_{5}$, adding each morning about $10 \mathrm{~g}$ of fresh reagent. Recently, drying of amides using Vitrid, sodium bis(methoxy-2-ethoxy)aluminohydride, has been recommended (Ref. 25). In DMF it allows attainment of very basic media ( $\mathrm{pH} 30$ ). However, distillation of the solvent from the mixture obtained has not been attempted and is probably very hazardous. Whatever the method used, it is important to proceed with these operations in a dark room or apparatus to prevent any photochemical degradation.

2. Neutralization. Depending on the drying agent used, it has been recommended that the basic or acidic impurities produced are neutralised, either by shaking with picric acid (Ref. 20 ) or $\mathrm{KOH}$ pellets (Ref. 24). This last treatment is particularly recommended after drying over $\mathrm{P}_{2} \mathrm{O}_{5}$ which generates formic acid. Such neutralization can be done either before or after a first distillation.

3. Distillation. The drying process can be further carried out during this operation. The DMF is refluxed and distilled from $\mathrm{P}_{2} \mathrm{O}_{5}$ or $\mathrm{CaH}_{2}$. However, owing to a degradation process increased by heating, it is preferable first to decant the solvent and transfer it under dry nitrogen, and then to distil it at reduced pressure.

The quality of the final product is greatly affected by the care with which the distillation is carried out. It seems to be important to work under vacuum, with a darkened column, or in a pure nitrogen or argon atmosphere. As a rule, the temperature must be kept under $60^{\circ} \mathrm{C}$; heating must be gentle and overheating avolded: Distillation in daylight results in the production of hydrogen cyanide (Ref. 5), particularly in the presence of $\mathrm{CaH}_{2}$. No traces of HCN are detected if the operations are conducted in the dark.

Types of distillation apparatus currently described in the literature do not seem to be very efficient. It is not surprising to note that the best quality DMF, if conductivity is accepted as a test of purity, has been obtained by Brummer (Ref. 12), who used only molecular sieves as drying agents, but carried out the distillation in a slow current of dry nitrogen at low pressure ( 2 torr) and an efficient column ( 1 meter packed with Fenske helices). The use of a long column ( $60 \mathrm{~cm}$ at least) with good packing and reflux is recommended. For example, Tanaka (Ref. 21) distilled DMF which had been dried over anhydrous $\mathrm{CuSO}_{4}$ at a pressure of 5 torr through an adiabatic fractional distillation column which was $1.3 \mathrm{~cm}$ in diameter, $120 \mathrm{~cm}$ in length and packed with helipack coils. Dry nitrogen was passed through the apparatus during the distillation; $60 \%$ of the distillate was collected. The conductivity was lower than $1 \times 10^{-7} \Omega^{-1} \mathrm{~cm}^{-1}\left(25^{\circ} \mathrm{C}\right)$. Boiling temperatures at various pressures are given in Table 1 . 
TABLE 1. Recommended values for physical constants of DMF at $25^{\circ} \mathrm{C}$ and 1 atm (except where noted otherwise)

Boiling temperature

$\mathrm{T}_{\mathrm{B}}$ $152.3^{\circ} \mathrm{C}(\operatorname{Ref} .47)$

$79^{\circ} \mathrm{C}$ at $61-62$ torr (Ref. 37)

$55-56^{\circ} \mathrm{C}$ at $25-26$ torr (Ref. 40)

$34^{\circ} \mathrm{C}$ at 2-3 torr (Ref. 15)

Melting temperature

Refractive index (Ref. 44)

$\mathrm{T}_{\mathrm{M}}$

$\mathrm{n}_{\mathrm{D}}^{25}$

$-61^{\circ} \mathrm{C}$

1.42689

Dielectric constant

Surface tension (Ref. 45)

Viscosity (Ref. 23)

Density

Molal volume

Heat capacity at constant pressure (Ref. 44)

Cubic expansion coefficient

Adiabatic compressibility coefficient (Ref. 44)

Isothermal compressibility coefficient
D

$\sigma$

$n$

$\rho$

V

$c_{p}$

$\alpha_{p}$

${ }^{B} \mathrm{~S}$

${ }^{B_{T}}$
37.0

37.1 dyne/cm

0.00796 poise

$0.9440 \mathrm{~g} \mathrm{~cm}^{-3}$

$77.39 \mathrm{~cm}^{3}$

$37.4 \mathrm{cal} / \mathrm{mol}$

$1.00 \times 10^{-3} \mathrm{~K}^{-1}$ *

$6.1 \times 10^{-5} \mathrm{~atm}^{-1}$

$6.3 \times 10^{-5} \mathrm{~atm}^{-1}$ *

*Calculated from data in Ref. (12)

4. Elimination of gaseous impurities. A flow of pure dry nitrogen or argon is passed through the solvent for several hours, in order to eliminate oxygen, carbon monoxide and carbon dioxide. Such a solvent can then be used for polarographic purposes. A more complete deaeration can be achieved using a vacuum line.

5. Conclusions and recommendations. As various authors used different starting materia1s, it is difficult co compare the efficiency of the vaj lous methods of purification. Comparison between different ways of treating the same batch of solvent can be found to our know ledge in only two papers (Ref. 11 and 20). Thomas and Rochow (Ref. 11) always used first azeotropic distillation with benzene and compared subsequent treatment with $\mathrm{MgSO}_{4}, \mathrm{BaO}$, alumina and triphenylchlorosilane, followed in each case by distillation. Comparisons were made in terms of specific conductance and water content. Barium oxide as well as alumina treatment meet rather well these two criteria and do not have any side effects, such as producing dimethylamine or $\mathrm{HCN}$. Juillard (Ref. 20) compared drying with $\mathrm{Na}_{2} \mathrm{CO}_{3}, \mathrm{Na}_{2} \mathrm{SO}_{4}$ or molecular sieves with azeotropic distillation with benzene and distillation over $\mathrm{P}_{2} \mathrm{O}_{5}$. As far as conductivity and water content are concerned, the different batches of solvent thus obtained were of about the same quality, except that $\mathrm{P}_{2} \mathrm{O}_{5}$ has the disadvantage of promoting degradation of the solvent and thus of decreasing the efficiency of the distillation; therefore the use of $\mathrm{P}_{2} \mathrm{O}_{5}$ is not recommended. As a confirmation it can be noted that authors using $\mathrm{P}_{2} \mathrm{O}_{5}$ or $\mathrm{CaH}_{2}$ as drying agents did not obtain purer solvents than those who employed BaO or $\mathrm{Na}_{2} \mathrm{CO}_{3}$ or even only molecular sieves.

It is therefore recommended that use is made first either of azeotropic distillation with benzene, as suggested by Thomas (Ref. 11), or of treatment with molecular sieves, as suggested by Ritchie (Ref. 17), and that the resulting DMF is then shaken with $\mathrm{Na}_{2} \mathrm{CO}_{3}$ or, better, with $\mathrm{BaO}$ for 1 or 2 days. After decantation the DMF is distilled twice under nitrogen (pressure $<15$ torr) using a $1-\mathrm{m}$ column. All these operations must be carried out in the dark. After deaeration the solvent is stored under nitrogen and used as soon as possible. 
Owing to its various modes of degradation (hydrolysis, thermal and photochemical decomposition) the principal impurities found in DMF are: dimethylamine, formic acid, hydrogen cyanide, carbon dioxide and carbon monoxide. To this list must be added: water, oxygen, which is quite soluble, and impurities resulting from the purification process.

Conductivity. As stressed earlier, hydrolysis as well as decomposition results in ionic impurities: dimethylammonium formate, carbonate or cyanide. Thus, the conductivity of the solvent is a very good test of its purity.

Experimental conductivities recorded in DMF are always higher than those reported for other aprotic solvents such as ketones or nitriles. According to a rough estimate, the theoretical conductivity of the solvent should be below $10^{-13} \Omega^{-1} \mathrm{~cm}^{-1}$. In fact, conductivities obtained by the most careful workers are scarcely ever less than $10^{-7}$. The best values have been reported, to our knowledge, by Brummer (Ref. 12) who used for conductometric studies a solvent having conductivities varying from $2 \times 10^{-8}$ to $5 \times 10^{-8} \Omega^{-1} \mathrm{~cm}^{-1}$. Values below $5 \times$ $10^{-7}$ have been reported by numerous authors and any batch of DMF which is more conducting can be considered to be impure.

Water. Water can be titrated by the Karl Fischer (K-F) reagent. Kanatharan (Ref. 22) recommends that the titration is conducted slowly, since $\mathrm{K}-\mathrm{F}$ reagent reacts only slowly with small amounts of water.

Usual procedures do not allow the determination of less than $10 \mathrm{ppm}$ of water. According to Muroi (Ref. 26) it is possible to titrate as little as $0.2 \mathrm{ppm}$ by increasing the sharpness of the end point, using the following procedure: "Add a 10-30 ml sample to $25 \mathrm{ml} \mathrm{MeOH}$ containing $8 \%$ of a pyridine- $\mathrm{SO}_{2}$ solution ( $320 \mathrm{~g} \mathrm{SO}_{2} / 1$ pyridine) and titrate potentiometrically with $\mathrm{K}-\mathrm{F}$ reagent having a titre of $0.1-0.5 \mathrm{mg} \mathrm{H} \mathrm{O} / \mathrm{ml}$ ". The use of DMF as a solvent for $\mathrm{K}-\mathrm{F}$ reagent also has been advocated (Ref. 27).

Prue (Ref. 23) has titrated water in DMF using triphenylsilyl chloride, from which, according to Thomas (Ref. 11), hydrogen chloride is liberated quantitatively by water (amines or acids are thought to interfere); the $\mathrm{HCl}$ content is then estimated from the conductivity of the solution.

It is quite easy to prepare a solvent which contains less than $50 \mathrm{ppm}$ of water. Very low concentrations (<5pm) are more difficult to attain. The best value, less than $3 \mathrm{ppm}$, has been reported by Libbey and Stock (Ref. 28).

Dimethylamine. Colorimetric methods have been used by some authors. In our opinion, as long as the autoprotolysis constant of the solvent is not known, it is not possible to say exactly what is basic and what is acidic in DMF. Kolthoff (Ref. 24) has used p-nitrophenol in the colorimetric determination of total basicity, but specific determinations would be preferable.

Thomas and Rochow (Ref. 11) have based the determination of the amine content on the fact that dimethylamine forms with 1-fluoro-2,4-dinitrobenzene a complex which absorbs in the visible spectrum at $3812 \AA$. Solvent prepared by Chang and Criss (Ref. 29) was found to contain less than $1 \mathrm{ppm}$ of dimethylamine using this method.

Another spectrophotometric method which allows the determination of the dimethylamine content down to $2 \mathrm{ppm}$ with an error of $\pm 10 \%$ has been proposed by Pribyl (Ref. 30 ); dimethyldithiocarbamate, which absorbs at $445 \mathrm{~nm}$, is formed by adding $\mathrm{CS}_{2}$ and $\mathrm{Cu}(\mathrm{AcO})_{2}$ to an EtOHpyridine mixture.

Chromatography was thought by Butler (Ref. 18) not to be a reliable means of establishing the organic impurity content of the solvent since DMF can decompose or hydrolyze at high temperatures. Nevertheless, careful studies of the proper experimental conditions have been undertaken (Ref. 31 and 32). In the paper by Filippov (Ref. 32) it is shown that dimethy1amine can be determined in DMF at levels as low as 1 ppm using tetrahydroxyethylenediamine as a stationary phase, polysorb-1 as a solid support and a column temperature of $75^{\circ} \mathrm{C}$.

Dimethylamine is not electroactive with mercury but can give coordination compounds with cations which will affect the course of electrochemical reductions.

Formic Acid. In contrast to dimethylamine, formic acid is electroactive. Kanatharan and Spritzer (Ref. 22) have attributed to formic acid two peaks, one cathodic, the other anodic, which appear in cyclic voltammograms of aqueous dimethylformamide. Alternating current polarography (Ref. 33), and, better, pulse polarography, can be used to estimate the formic acid content. 
Formic acid can also be determined by titration with a base. Potentiometric titration is preferred since it allows determination of the dimethylammonium formate content as well. Megliskii (Ref. 34) has titrated potentiometrically formic acid, dimethylamine and dimethylammonium formate in DMF using two solutions: $0.1 \mathrm{M} \mathrm{HClO} 4$ and $0.1 \mathrm{M} \mathrm{KOH}$, both in alcohol. Such a method is suitable only for concentrations of the order of at least $100 \mathrm{ppm}$.

Hydrogen Cyanide. Trisler et al. (Ref. 5) reported the presence of HCN in DMF distilled over $\mathrm{CaH}_{2}$ in natural light. Concentrations ranged from $10^{-5}$ to $10^{-3} \mathrm{M}$. Spectrophotometric titration can be carried out with 4-nitrobenzil, which reacts with cyanide ion to form a deep violet ion.

Oxygen. Oxygen is rather soluble in DMF. A study of oxygen solubility in relation to the oxygen content of the gas phase has been made by James (Ref. 35). When the gas phase was air and pure oxygen, the solubility was $2.2 \times 10^{-3}$ and $3.1 \times 10^{-3} \mathrm{M}$, respectively.

Oxygen is an electroactive impurity which interferes in polarography and other electrochemical processes. Two waves are observed (Ref. 36) with $E_{1} / 2=-0.8$ and $-2.8 \mathrm{~V}$ vs. SCE; the first corresponds to the reduction of oxygen to superoxide:

$$
\mathrm{O}_{2}+\mathrm{e}^{-} \longrightarrow \mathrm{O}_{2}^{-}
$$

and the second one to the reduction of superoxide to peroxide ion:

$$
\mathrm{O}_{2}^{-}+\mathrm{e}^{-} \longrightarrow \mathrm{O}_{2}=
$$

James (Ref. 35) has proposed two methods for the determination of the oxygen concentration; polarography and the Winkler method. Polarographic measurements are made at $-1.2 \mathrm{~V}$ vs. SCE, in order to ensure that the measured diffusion current is not influenced by a polarographic maximum. A modified Winkler method allows concentrations as low as $10 \mathrm{ppm}$ to be determined. It depends upon quantitative oxidation of iodide ion to iodine. Such a process is described in some detail (Ref. 35).

\section{PHYSICAL PROPERTIES OF DIMETHYLFORMAMIDE}

Numerical values of physical constants are highly dependent on the purity of the solvent. Consequently, important discrepancies are found in the literature. The present recommended values result from a careful examination of three aspects: accuracy of the measurements, consistency of the data of various authors at different temperatures, and purification of the solvent. Such a choice is subject to personal evaluation and it seems prudent to give also the other references.

Density. The density is probably a good criterion of the purity of the solvent. Contamination with water increases the density (Ref. 23). The following values of the density at $25^{\circ} \mathrm{C}$ have been found (Ref. 23,8,37,12): $0.9439,0.9440_{2}, 0.9441_{5}$ and $0.9442 \mathrm{~g} \mathrm{~cm}^{-3}$, respectively. 0ld values greater than 0.9443 frequently found in tables are probably too high. New work by Kawaizumi and Zana (Ref. 38) seems to indicate that the density of the pure solvent is lower. These authors obtain values ranging from 0.94360 to 0.94368 . It is our feeling that these data are more accurate than previous ones but such a low value $(\rho=0.94364 \pm$ 0.00004 ) must be confirmed by others before being accepted.

Values at various temperatures other than those appearing in Table 2 have been given by Gopal and Rizvi (Ref. 39). At $20^{\circ} \mathrm{C}$ Saphon (Ref. 40) has obtained $\rho=0.94878 \mathrm{~g} \mathrm{~cm}^{-3}$, in good agreement with the value in Table 2 .

TABLE 2. Recommended values for physical constants of DMF at various temperatures

\begin{tabular}{lllll}
\hline & & $\rho$ & \\
& & $\mathrm{g} \mathrm{cm}^{-3}$ & $\begin{array}{l}\eta \\
\text { poise }\end{array}$ & \\
Temperature & $20^{\circ} \mathrm{C}$ & 0.9488 & 0.00845 & 38 \\
& $30^{\circ} \mathrm{C}$ & 0.9394 & 0.00746 & 36.1 \\
& $40^{\circ} \mathrm{C}$ & 0.9298 & 0.00664 & 34.4 \\
Reference & $50^{\circ} \mathrm{C}$ & 0.9202 & 0.00598 & 32.8 \\
& & 12 & 49 & 1 \\
\hline
\end{tabular}

Viscosity. Other values can be found in References (29) and (41). Prue's data at $25^{\circ} \mathrm{C}$ are confirmed by measurements reported by Ames and Sears (Ref. 42). 
Dielectric constant. Data given by Bass and Cole (Ref. 1) are preferred to previous results (Ref. 43) of Leader and Gormley $\left(36.71\right.$ at $25^{\circ} \mathrm{C}$ ). The value reported at $25^{\circ} \mathrm{C}$ is interpolated from measurements at various temperatures. Data of Saphon (Ref. 40) are in good agreement with the value reported in Table 2 at $20^{\circ} \mathrm{C}(\mathrm{D}=38.13)$.

Miscellaneous. Data at various temperatures concerning refractive index, surface tension and isothermal compressibility can be found in Refs. (44), (45) and (12), respectively. Other data concerning thermodynamic properties are reported in Refs. (39) and (44). Plots of vapor pressure, heat of vaporization, heat capacity, density, viscosity, surface tension and thermal conductivity for a large range of temperature have been drawn up by Gallant (Ref. 46). The solubilities of some sixty substances in DMF have been tabulated (Ref. 50). Organic reactions in or with DMF have been summarized (Ref. 51).

\section{REFERENCES}

1. S. J. Bass, V. I. Nathan, R. M. Meigham and R. H. Cole, J. Phys. Chem., 68, 1509 (1964).

2. V. Gutmann, Coordination Chemistry in Non-Aqueous Solutions, Springer Verlag (1968), p. 152 .

3. M. Bréant, M. Bazouin, C. Buisson, M. Dupin and J. M. Rebattu, Bull. Soc. Chim. France, 5065 (1968).

4. J. Kroh, E. Burzynska, Bull. Acad. Polon. Sci., Sc. Chim., 21, 289 (1973).

5. J. C. Trisler, B. F. Freasier and Shi-Ming Wu, Tetrahedron Letters, 687 (1974).

6. Ram Chand Paul, P. S. Guraya and B. R. Sreenathan, Indian J. Chem., 1, 335 (1963).

7. M. Bréant and G. Demange-Guérin, Bull. Soc. Chim. France, 2935 (1969).

8. E. Lolette and J. Juillard, J. Sol. Chem., 3, 127 (1974).

9. H. E. Stokinger, Documentation of Threshold Limit Values, revised ed., American Conference of Governmental Industrial Hygienists, Cincinnati, Ohio (1966).

10. J. W. Vaughn in The Chemistry of Non-Aqueous Solvents, ed. J. J. Lagowski, Academic Press, New York (1967) Vol. II, P. 243.

11. A. P. Thomas and E. G. Rochow, J. Amer. Chem. Soc., 79, 1843 (1957).

12. S. B. Brummer, J. Chem. Phys., 42, 1636 (1965).

13. N. S. Moe, Acta Chem. Scand., 21, 1389 (1967).

14. S. C. Chan and J. P. Valleau, Can. J. Chem., 46, 853 (1968).

15. D. A. Owensby, A. J. Parker and J. W. Diggle, J. Amer. Chem. Soc., 96, 2682 (1974).

16. J. N. Butler, J. Phys. Chem., 72, 3288 (1968).

17. C. D. Ritchie and G. H. Megerle, J. Amer. Chem. Soc., 89, 1447 (1967).

18. J. N. Butler, J. Amer. Chem. Soc., 92, 2602 (1970).

19. 0. N. Bhatnager and C. M. Criss, J. Phys. Chem., 73, 174 (1969).

20. J. Juillard, J. Chim. Phys., 67, 691 (1970).

21. N. Tanaka, personal communication.

22. P. Kanatharan and M. S. Spritzer, Anal. Letters, 6, 421 (1973).

23. J. E. Prue and P. J. Sherrington, Trans. Faraday Soc., 57, 1795 (1961).

24. I. M. Kolthoff, M. K. Chantooni, Jr., and H. Smagowski, Anal. Chem., 42, 1622 (1970).

25. M. Bréant, Journées d'Electrochimie, Rouen (France), 10 Avril 1975; M. Bréant and J. Georges, C. R. Acad. Sc. Paris, Série C 280, 33 (1975).

26. K. Muroi, M. Ono, Bunsek1 Kagaku, 20, 975 (1971).

27. V. A. Klimova, F. B. Sherman and A. M. L'vov, Isvest. Akad. Nauk SSSR, Ser. Khim., 2599 (1967).

28. A. J. Libbey and J. T. Stock, Anal Chem., 42, 526 (1970).

29. S. Chang and C. M. Criss, J. Sol. Chem., 2 , 457 (1973).

30. N. Pribyl and J. Nedbalkova, Fresenius'Z. Anal. Chem., 232, 261 (1967).

31. V. A. Zverev and G. A. Krestov, Isv. Vyssh. Uchebn. Zavedenii, Khimiya i Khim: Tekhnol, 963 (1968).

32. Yu S. Filippov and Ya A. Tsarfin, Zh. Anal. Khim., 26, 1644 (1971).

33. A. Francina, Thèse Docteur-ès-Sciences, Lyon (France), 1973, p. 72.

34. V. A. Meglitskii and N. n. Kvasha, Khim. Volokna, 70 (1971).

35. H. J. James and R. F. Broman, Anal Chim. Acta., 48, 411 (1969).

36. D. L. Maricle and W. G. Hodgson, Anal. Chem., 37, 1562 (1965).

37. C. M. French and K. H. Glover, Trans. Faraday Soc., 51, 1418 (1955).

38. Personal communication of numerical values used in the paper by $F$. Kawaizumi and $R$. Zana, J. Phys. Chem., 78, 1099 (1974).

39. Ram Gopal and S. A. Rizvi, J. Indian Chem. Soc., 43, 179 (1966).

40. S. Saphon and H. J. Bittrich, Z. Phys. Chem., Leipzig, 252, 113 (1973).

41. Ram Gopal and P. P. Rastogi, Z. Phys. Chem. N.F. (Frankfurt), 69, 1 (1970).

42. D. P. Ames and P. G. Sears, J. Phys. Chem., 59, 16 (1955).

43. G. R. Leader and J. F. Gormley, J. Amer. Chem. Soc., 73, 5731 (1951).

44. B. E. Geller, Zh. Fiz. Khim., 35, 2110 (1961).

45. R. A. Stairs, W. T. Rispin and R. C. Makhija, Can. J. Chem., 48, 2755 (1970).

46. R. W. Gallant, Hydrocarbon Processing, 48, 199 (1969).

47. B. V. Ioffe, Zh. Obshch. Khim., 25, 902 (1955).

48. J. R. Ruhoif and E. E. Reid, J. Amer. Chem. Soc., 59, 4012 (1937).

49. L. R. Dawson and W. W. Wharton, J. Electrochem. SoC., 107700 (1960).

50. Ram Chand Paul and B. R. Sreenathan, Ind. J. Chem., $4, \frac{4}{382}$ (1966).

51. R. S. Kittila, Dimethylformamide: Chemical Uses, E. I. duPont de Nemours and Co. (1967). 